\title{
An Integrated Modeling Approach for Analyzing the Deformation Style of Active Volcanoes: Somma-Vesuvius Case Study
}

3 Ada De Matteo ${ }^{1,2}$, Bruno Massa ${ }^{2}$, Raffaele Castaldo ${ }^{1}$, Luca D'Auria ${ }^{3,4}$, Mike R.

4 James $^{5}$, Stephen J. Lane ${ }^{5}$, Susi Pepe ${ }^{1}$, and Pietro Tizzani ${ }^{1}$

$5 \quad{ }^{1}$ Consiglio Nazionale delle Ricerche, Istituto per il Rilevamento Elettromagnetico

6 dell'Ambiente, CNR-IREA, Napoli, 80124, Italy.

7 2Dipartimento di Scienze e Tecnologie, Università degli Studi del Sannio, Benevento,

8 82100, Italy, ORCID ID: 0000-0002-7358-1841 (B.M.) 0000-0002-8895-7549

9 (A.D.M.).

$10{ }^{3}$ Instituto Volcanológico de Canarias (INVOLCAN), 38320, San Cristóbal de La

11 Laguna, Santa Cruz de Tenerife, Canary Island, Spain.

12 Instituto Tecnológico y de Energías Renovables (ITER), Environmental Research

13 Division, 38600, Granadilla de Abona, Santa Cruz de Tenerife, Canary Islands, Spain.

$14{ }^{5}$ Lancaster Environment Centre, Lancaster University, Lancaster, LA1 4YQ, United

15 Kingdom.

16 Corresponding author: Pietro Tizzani (tizzani.p@irea.cnr.it), ORCID ID: 0000-0001-

$17 \quad \underline{9745-5674}$

\section{Key Points:}

1. Analog and numerical modeling highlight an active spreading-sagging process at the Somma-Vesuvius volcano.

2. A comparison of models with DInSAR deformation data validates the modeling procedures.

3. The spreading at Vesuvius allows inference of the near-future eruption style, due to the loading stress reduction generated by the tension regime condition affecting the chemistry and explosivity index of volcanic eruptions. 


\section{Abstract}

28 The deformation style of active volcanoes can provide insight into the structural

29 evolution of their edifices, volcanic activity and associated hazards. The Somma-

30 Vesuvius volcano is considered one of the most dangerous on the planet due to its

31 proximity to the megacity of Naples (Southern Italy). Thus, understanding its

32 deformation style and corresponding long-term structural evolution are critical aspects

33 for risk reduction. Although a large amount of data has already been collected about

34 Somma-Vesuvius, the deformation style affecting its volcanic edifice is still debated.

35 Therefore, we devised an integrated approach to clarify the current state of deformation

36 of this volcano. In particular, we combined analog experiments and finite element (FE)

37 modeling to constrain the current deformation style affecting Somma-Vesuvius and

38 determine the physical parameters controlling its structural evolution. The analog

39 models were built at a scale of 1:100,000 using sand mixtures (brittle analog) and

40 polydimethylsiloxane (ductile analog). The FE models were implemented by

41 considering a three-dimensional time-dependent fluid-dynamic approach performed at

42 both the analog model scale (1:100000) and actual volcano scale (1:1). We obtained an

43 FE model and a corresponding analog one that faithfully reproduced the observed

44 deformation velocity patterns revealed by differential interferometric synthetic aperture

45 radar (DInSAR) and GPS measurements at Somma-Vesuvius. Overall, our results

46 support the hypothesis that a combined gravitational spreading-sagging process governs

47 the deformation style of Somma-Vesuvius.

Volcanic edifices of sufficient mass are capable of deforming substrata under their own weight; this deformation in turn can deform the volcanic edifices themselves. Identifying the deformation style characterizing a volcanic edifice is useful when considering the evolution of its volcanic activity. Vesuvius is considered one of the most dangerous volcanoes on the planet due to its proximity to the megacity of Naples (Southern Italy). Thus, understanding its deformation style and corresponding structural evolution are critical aspects for risk reduction. In order to analyze the deformation process of Vesuvius we used two different modeling techniques: analog modeling and Finite Element numerical modeling. The analog modeling approach allows us to reproduce real processes by using scaled models and media considered analog to natural materials under a physical point of view. The combination of analog and numerical modeling allowed us to constrain the current deformation style affecting SommaVesuvius and to determine the physical parameters controlling its structural evolution. Finally we compared our results with the observed deformation velocity patterns revealed by Differential Interferometric Synthetic Aperture Radar and GPS measurements at Vesuvius. Overall the results support the hypothesis that a combined gravitational spreading-sagging process governs the deformation style of SommaVesuvius.

Keywords: Volcano Deformation, Spreading, Sagging, Analogue Model, Finite Element Analysis, Gravitational Deformation.

\section{$71 \quad 1$ Introduction}

Volcanic edifices can have sufficient mass to deform their substrata, which in turn can deform the volcanic edifices themselves. Identifying the deformation style characterizing a volcanic edifice is useful because it can influence seismic and volcanic activity (Borgia et al., 2000; D’Auria et al., 2013). Borgia et al. (2005) proposed an 
active spreading deformation hypothesis for the Somma-Vesuvius volcanic complex based on observational evidence: (i) Seismic profiles and gravimetric and magnetic surveys of the area showed that the recent strata are folded and cut by minor thrust faults (Andronico et al., 1995). (ii) Leveling surveys along a profile parallel to the coastline from Napoli to the Sorrento Peninsula (Osservatorio Vesuviano, INGV, internal reports 1990-2000; Lanari et al., 2002; Borgia et al., 2005) revealed a strong subsidence (almost $2 \mathrm{~mm} / \mathrm{yr}$ ) of Vesuvius and uplift (about $2 \mathrm{~mm} / \mathrm{yr}$ ) of the Pompeii area. (iii) DInSAR data from Somma-Vesuvius highlighted a regional scale subsidence that terminated at Pompeii, where a relative uplift was evident. Despite this evidence, the deformation style affecting Somma-Vesuvius is still debated.

\subsection{Theoretical background}

During the last decades, several studies have focused on the structural evolution and deformation processes of volcanic edifices (e.g., Merle \& Borgia, 1996; van Wyk de Vries \& Matela, 1998; Byrne et al., 2013; Delcamp et al., 2008; Kervyn et al., 2010). Analog and numerical modeling have highlighted the roles of rheology, volcanotectonic features, basement geology and the sedimentary successions beneath volcanoes in defining the deformation styles of volcanic edifices.

Reliable modeling approaches require preliminary measurements of the natural phenomena and ground deformation analyses are fundamental in determining deformation styles. Such measurements can be used to constrain both analog and numerical models, which can generally aid each other in improving parameter estimation through several iterative simulations. At the end of modeling procedures, the models are usually compared with observed data to validate results (Kavanagh et al., 2018). The outcomes of such models are helpful for evaluating and forecasting potential volcanic hazards, such as flank collapses (e.g., van Wyk de Vries \& Matela, 1998).

As volcanoes grow through the accumulation of erupted products, their increasing gravitational loads can exceed the mechanical strengths of volcanic substrata. Supposing that an edifice lies on a brittle layer that overlies a ductile layer (e.g., sedimentary successions), a horizontal outward deformation of the ductile substratum can result, in turn inducing a vertical displacement of the edifice. Such gravitational deformation is mainly controlled by the rheological proprieties of substrata and their thicknesses (Merle \& Borgia, 1996; van Wyk de Vries \& Borgia, 1996). The thickness ratio between a ductile layer and a brittle layer determines the deformation style of the edifice, resulting in either flexure, sagging (also called basement extrusion), or spreading (van Wyk de Vries \& Matela, 1998; Byrne et al., 2013; Fig. 1).

The flexure deformation style occurs when the thickness of the ductile layer beneath an edifice is significant compared with the edifice dimensions and brittle layer thickness. The ductile layer is not horizontally constrained by boundaries, and the edifice deformation is characterized by a significant vertical downward displacement. This leads to the development of normal faults at the base of the edifice, a compression of the whole edifice and a flexural bulge surrounding the edifice (Fig.1b.3).

In the case of sagging deformation, the deformation rate is determined by the gravitational load, edifice geometry and flexural rigidity of the basement. A pure sagging deformation is characterized by a peripheral horizontal extension of the area surrounding the volcano, associated with edifice compression (van Wyk de Vries \& Matela, 1998; Byrne et al., 2013). It occurs when the ductile layer viscosity is low compared with the strength of the overlying brittle layer. In this case, there is still outward movement of the ductile material but not an associated outward displacement 
124 of the volcanic slopes. As the underlying material moves away from an edifice, the edifice sags downwards and undergoes overall compression (Fig.1b.2). Finally, the spreading deformation style requires the presence of a weak ductile substratum (e.g., sedimentary successions, pyroclastic rocks, or oceanic crust affected by hydrothermal activity or partial melting) and a relatively high mass loading from an edifice. In this case, spreading is accommodated by thrust faulting around the base of the edifice and graben-style faulting at its center, in addition to a ductile flow of the weak underlying layer (Delcamp et al., 2008; Fig. 1a; 1b.1). Volcanic spreading tends to be independent of the regional tectonic setting because, locally, the volcano-tectonic stress field overcomes the regional one (Borgia et al., 2000). Generally, the spreading style can be summarized as a deformation characterized by the subsidence of the summit or upper flanks of a volcano, outward displacement at the slopes, periphery, and nearby substrate, and formation of summit horst-and-graben structures, basal thrusts, and folds (Borgia et al., 2000).

138 The transition from the flexure style to spreading style depends on the relationship between the thickness and viscosity of the ductile layer. Spreading-style deformation can occur if there is a thin ductile layer with a high ratio of its viscosity to the volcano failure strength (van Wyk de Vries \& Matela, 1998; Fig. 1b.1). Otherwise, if there is a thin ductile layer but the ratio between the viscosity of the ductile substratum and the failure strength of the edifice is low, the edifice experiences sagging deformation (Byrne et al., 2013; van Wyk de Vries \& Matela, 1998; Fig. 1b.2). Low-viscosity ductile layers generally represent substrata that are decoupled from the edifice and are extruded from underneath it. In this case, the edifice sinks and is subject to an overall compressional stress field. Finally, the presence of a basal thick ductile layer allows the edifice to deform with a flexure style (van Wyk de Vries \& Matela, 1998; Fig. 1b.3). A pure spreading deformation reduces the likelihood of sector collapses by reducing cone stresses by forming inward dipping normal faults and reducing slope angles (van Wyk de Vries \& Borgia, 1996). Spreading-related processes range from rock creeps to large-magnitude earthquakes (Borgia et al., 2000). In contrast, basement extrusion deformation results in high compressive cone stresses, which can lead to the formation of outward dipping faults, and maintains or steepens existing slopes, thus increasing the risks of flank collapse (van Wyk de Vries \& Francis, 1997).

\subsection{Geological setting}

The Somma-Vesuvius volcano complex of the Neapolitan volcanic district comprises explosive and effusive products (Borgia et al., 2005). It is characterized by the asymmetric shapes and truncated cone of Mt. Somma, remnants of various calderaforming eruptions, and the smaller cone of Vesuvius Gran Cono, which grew in the last two millennia and is offset from the axis of Mt. Somma (Bonasia et al., 1985; Fig. 2). The oldest evidence of Mt. Somma-Vesuvius activity dates back to $0.369 \pm 0.028 \mathrm{Ma}$ (40Ar/39Ar) (Jashemsky, 2002), and its last eruption occurred in 1944. SommaVesuvius grew on a substratum consisting of Mesozoic carbonates displaced by SWand NW-dipping normal fault systems and, secondarily, by NE-SW and E-W faults (Fusi et al., 1991; Brocchini et al., 2001; D'Auria et al., 2014a; see also the detailed geological map in Sbrana et al. 2020). NW-SE, NE-SW, and ENE-WSW faulting also affect the volcanic units cropping out in the Somma caldera (Santacroce, 1987; Borgia et al., 2003; D'Auria et al., 2014a; Fig. 2). Somma-Vesuvius is currently quiescent, showing only fumarolic activity, low-energy seismicity (Ventura \& Vilardo, 1999), and slow ground deformation. The latter is characterized by the subsidence of the edifice 
173 and uplift in the surrounding area (Lanari et al., 2002; Borgia et al., 2005; Marturano et 174 al., 2013).

175 The hypothesis of the active spreading deformation at Somma-Vesuvius was first proposed by Borgia et al., (2005). Seismicity at Somma-Vesuvious can be separated into two seismogenic volumes, located at different depths and dominated by different stress patterns (Bianco et al., 1998; D'Auria et al., 2014). The seismicity in the lower volume is confined between about 1 and $5 \mathrm{~km}$ b.s.l. and is related to the background regional stress field. In contrast, seismicity in the upper volume, located above sea level, can be related to the gravitational deformation of the edifice (D'Auria et al., 2014). In this work, to understand the deformation style at Somma-Vesuvius better, we built an original set of analog and finite element (FE) scale models to reproduce the deformation processes currently active at Mt. Somma-Vesuvius. DInSAR measurements derived from ERS-1/2 and ENVISAT SAR data during 1993-2010 were used as constraints in the modeling procedure. The analyses of DInSAR mean velocity maps and the corresponding time series (dataset from Tizzani et al., 2020) allowed us to obtain a reliable picture of the active deformation processes at Somma-Vesuvius and their temporal evolution. Figure 3 shows sensor line of sight (LOS) mean velocity maps along ascending and descending orbits. The processed data are relevant to the complete SAR image catalogs of ERS-1/2 and ENVISAT from 1993 to 2010, and they highlight three main aspects of the ground deformation patterns of Somma-Vesuvius: (i) subsidence on the summit area, (ii) generalized subsidence of the S-SW flank of the edifice and a semi-circular area surrounding the volcano spanning from NW to SE, and (iii) uplift of the area located at W-NW of the edifice and the area of Pompeii, located $\mathrm{SE}$, a few kilometers away from the volcanic edifice.

2 Methods

Analog models need to be scaled to faithfully represent volcano deformation processes (e.g., Hubbert, 1937; Ramberg, 1981). Our experiments were arranged with a main length scale ratio $\left(\mathrm{L}^{*}=\mathrm{L}\right.$ at the model scale/ $\mathrm{L}$ at the volcano scale) set at 1:100,000, a density ratio $\left(\rho^{*}=\rho\right.$ at the model scale/ $\rho$ at the volcano scale) set at 0.6 , and a gravity ratio $\left(\mathrm{g}^{*}=\mathrm{g}\right.$ at the model scale/g at the volcano scale) of 1 , resulting in a stress ratio $\left(\sigma^{*}\right.$ $=\sigma$ at the model scale $/ \sigma$ at the volcano scale) of:

$$
\sigma^{*}=\rho^{*} \times \mathrm{g}^{*} \times \mathrm{L}^{*} \approx 6 \times 10^{-6}
$$

206 Since cohesion has the same stress dimension ([Pa]), $\sigma^{*}$ also represents the scaling ratio for cohesion $\left(\mathrm{c}^{*}=\mathrm{c}\right.$ at the model scale/c at the volcano scale). This allows setting the sand mixture cohesion used for modeling ( $\sim 65 \mathrm{~Pa})$ to correspond to an unfractured rock with cohesion of $\sim 10 \mathrm{MPa}$ (Jaeger \& Cook, 1971; Handin, 1996).

In the context of scaling analyses, volcano deformation styles can be characterized using dimensionless analyses (Merle \& Borgia, 1996; van Wyk de Vries \& Borgia, 1996; Barenblatt, 2003; Tizzani et al., 2010; Gibbings, 2011). Such analyses entail relating the geometrical and physical parameters of a volcano through a set of dimensionless numbers derived based on the Buckingham $\prod$ theorem (Buckingham, 1914,1915 ). According to it, we selected eleven variables (volcano height, volcano base diameter, ductile layer thickness, brittle layer thickness, internal friction angle, ductile layer density, ductile layer viscosity, volcano bulk density, gravity acceleration, deformation velocity, and brittle material cohesion) and three dimensions (length, time, and mass) defining eight dimensionless numbers (Table 1). 
220 The dimensionless numbers $\left(\prod_{1}\right.$ to $\left.\prod_{5}\right)$ consider the geometrical characteristics, while $221 \prod_{7}$ and $\prod_{8}$ represent the force ratios. The numbers from $\prod_{5}$ to $\prod_{8}$ have a minor role in interpreting experimental results because they consider the brittle layer behavior (П5$\left.\prod_{7}\right)$ or the ductile layer $\left(\prod_{8}\right)$ alone. The numbers from $\prod_{5}$ to $\prod_{8}$ were only used for scaling.

\subsection{Analog modeling}

226

227

228

229

230

231

232

233

234

235

236

237

238

239

240

241

242

243

244

245

246

247

248

249

250

251

We realized twelve analog models. The first series of models $(60 \times 50 \mathrm{~cm}$ planar dimensions) were constrained by fixed walls and comprised two layers: a brittle upper layer (0.2-0.9-cm thick) made of a mixture of dry quartz-sand and K-feldspar powder (30\% in weight) as a bulking agent, and a lower ductile layer of polydimethylsiloxane (PDMS) with a thickness of 0.4-0.7 cm (Fig. 4a; Table 2). The volcanic edifice was represented by sand emplaced on the brittle layer. We constructed models that reproduced the asymmetric shape of the Somma-Vesuvius volcano, with a truncated cone analog of Mt. Somma topped by a smaller cone analog of Vesuvius Gran Cono, which was set off the axis of the central cone (Fig. $4 \mathrm{~b}$ and c). We used a higher density mix (quartz-sand and rutile powder; $50 \%$ in weight) for a few models, which helped widen the parameter space explored by the experiments (Table 2). To provide confidence in any asymmetry in results interpreted as due to edifice asymmetry, we also carried out control models with a symmetric edifice to provide a benchmark reference.

To estimate the vertical and horizontal deformations, we monitored the experiments using four digital cameras. Image sets were processed into sequences of 3-D surface models using structure-from-motion photogrammetry, allowing vertical deformation analyses (AgiSoft PhotoScan Professional, version 1.4.3; 21 July 2018. (C2018 Agisoft LLC). Horizontal deformation was assessed by tracking feature displacements within the vertical camera image sequence using the Pointcatcher software (www.lancaster.ac.uk/staff/jamesm/software/pointcatcher.htm; Delcamp et al., 2008; James et al., 2015).

Our twelve models comprised variations in brittle and ductile layers thickness and bulk density (Table 3). We also varied the symmetry of the volcanic edifice to provide a benchmark reference to the asymmetric ones.

\subsection{Finite element modeling}

We not only performed FE simulations to reproduce and validate the analog models but also to analyze the deformation affecting the volcanic edifice while using the same geometrical and physical characteristics of the analog models but with the dimensions of the Somma-Vesuvius volcano. Indeed, the numerical method is the only approach allowing a 1:1 scale simulation. The correspondence between the results of the numerical simulations reproducing the analog models and the numerical simulations made with the real dimensions of the volcano was a key result confirming the validity of our analog model. This correspondence could allow us to compare the results of our scaled analog model with the DInSAR data, thus demonstrating the actual deformations of the Somma-Vesuvius volcano.

Also, using the COMSOL Multiphysics ${ }^{\circledR}$ software package, we performed 3D timedependent fluid-dynamic models in an FE environment. FE simulations of the ground deformation velocities were performed using a Newtonian viscous flow approximation for the media behavior, which allowed us to evaluate how the thickness and viscosity 
267 contrast between the ductile and brittle domains modulated the observed gravity-driven 268 deformation. We first reproduced the analog experiments in the FE environment and 269 then reproduced the best model of the Somma-Vesuvius at natural scale (1:1), scaling 270 all parameters with the same scale factor used to build the analog models (see Section 2711.2 for details on scaling approach). To model the sand mixture, we approximated the rheology using a viscous approximation by applying "apparent viscosity" (i.e., ratio between the applied shear stress and the shear rate). The use of apparent viscosity can be considered a valid approximation when the material has a high cohesion value as in our analog experiments due to the addition of the bulking agent (see Section 2.2).

The FE models reproduced the analog experiments through domain dimensions of $60 \times$ $60 \times 10 \mathrm{~cm}$. We defined two regions of appropriate thickness to represent (1) the edifice topography and upper sand mixture and (2) the lower PDMS layer (e.g., Fig. 5a), which has a density of $\rho_{d}=965 \mathrm{~kg} \mathrm{~m}^{-3}$ and a viscosity of $\eta=2 \times 104$ Pa $\bullet$ (Weijermars, 1986). The sand mixture was represented by bulk density of $1550 \mathrm{~kg} \mathrm{~m}^{-3}$ (Montanari et al., 2017) and an apparent viscosity value of $0.8 \times 10^{8} \mathrm{~Pa}$ s. This apparent viscosity value was determined as the optimum from a series of FE tests. The cohesion of the brittle layer, thickness of the ductile layer, and DEM of the model were changed for each simulation based on the corresponding analog models.

We set free boundary conditions at the surface, roller conditions (movement only parallel to the boundary) at the four lateral sides, and fixed constraints at the bottom of the computational domain. The computational domain was discretized into tetrahedral elements (Fig. 5b), which enabled a fine meshing adapted to the complex topography. The domain was discretized into 164,800 tetrahedral elements ranging in size from $0.002 \mathrm{~m}$ to $0.01 \mathrm{~m}$, with the coarser elements located along with the boundaries of the domain. To validate the simulations of the analog models, we realized FE simulations at a real scale (i.e., 1:1), including the actual topography of Somma-Vesuvius. The digital topography was defined using the SRTM DEM of the volcano (Farr et al., 2007).

\section{Experimental results}

\subsection{Analog modeling results}

The benchmark reference symmetric models (i.e., models $02,03,05,07$, and 10 ) generated almost symmetric deformation patterns and gave confidence that asymmetry observed in other results reflected asymmetry in the edifice. Consequently, we focus our discussion on the asymmetric models $(01,04,06,08,09,11$, and 12; Table 3) with results most closely resembling the deformation of Somma-Vesuvius (for further information on all results, see Appendix A).

In model 01 (Fig. 6a), the whole model edifice generally subsided quite symmetrically by $0.25-0.5 \mathrm{~cm}$ but with peak values of almost $1.0 \mathrm{~cm}$. The area surrounding the edifice showed a little diffuse uplift with values of up to $0.25 \mathrm{~cm}$. The highest values, which ranged from 0.5 to $0.75 \mathrm{~cm}$, were located in a small circular area close to the base of the edifice.

In model 04 (Fig. 6b), the model edifice was characterized by a significant subsidence with values ranging from 0.75 to $1.0 \mathrm{~cm}$, showing a little asymmetric behavior, which was more prominent on the side of the Somma caldera rim. The whole area surrounding the model edifice had a gentle uplift with values of $\sim 0.25 \mathrm{~cm}$. In comparison, the area close to the base of the edifice showed high values, with an uplift of $\sim 1.0 \mathrm{~cm}$ arranged in concentric circular sectors. The surrounding area on the side close to the Somma caldera rim showed a relevant uplift (flexural bulge in section 1.2). 
315 In model 06 (Fig. 6c), the whole edifice had a prominent subsidence with peak values of $316 \sim 1.0 \mathrm{~cm}$, and the area close to its base was characterized by a diffuse uplift reaching 317 values of $\sim 1.0 \mathrm{~cm}$.

318 Model 08 (Fig. 6d) was characterized by an overall deformation comparable with that of model 01. Both models showed a subsidence of the whole edifice and an uplift of the area close to its base, while the surrounding area was subjected to a slight uplift. However, in contrast to model 01, the structures forming at the top and base of the edifice in model 08 clearly showed flexural bulges around the volcano and radial faults cutting the edifice from the center to the slopes.

324 Model 09 (Fig. 6e) is characterized by the general subsidence of the edifice along with 325 the formation of almost radial faults, which were more developed on the side with the 326 Somma caldera rim. As for the previous models, a dominant shear fracture separated the Somma caldera rim from the side of the edifice on which Vesuvius Gran Cono rises. An uplift was highlighted all around the edifice base but was greatest along the area close to the Somma caldera rim.

330 Model 11 (Fig. A1 in Appendix A), with a large edifice and a thin ductile layer (0.4 $\mathrm{cm}$ ), highlights the asymmetric gravitational deformation of the volcano due to its asymmetric shape. It shows a strong subsidence of the Vesuvius Gran Cono and Somma caldera rim as well as a really strong uplift of the surface close to the edifice on the side of the Somma caldera rim. This model is characterized by a flexural bulge, particularly on the Somma rim side, and by the formation of a few main radial faults.

336 Finally, the results of model 12 (Fig. 6f) are generally comparable with those of models 05 and 08. Still, the deformation affecting model 12 appears to be less prominent: the subsidence affected the whole edifice, and the uplift affected almost only the base of the volcano slopes. The edifice was not cut by a fault as in model 08. Conversely, faults were only formed at the edge of the subsiding area. Both the subsidence and uplift were less prominent than in the other models.

We focus our discussion on the asymmetric model results, which closely match the geometry of the Somma-Vesuvius asymmetric volcanic edifice (Table 3). Comparing the maximum positive velocities and the maximum negative velocities (Fig. 7d) confirmed that the edifice mass had a significant influence on determining the extent of the deformation pattern. An overall analysis (Fig. 7a-c) showed that Somma-Vesuvius (black star, whose value was derived from the analysis of the DInSAR data (sec. 1.2)) falls in the proximity of the point corresponding to model 08 , confirming a similar behavior (Fig. 7a-c).

The relationship between the area and velocity ratios (Fig. 7d) suggest that model 08 is the best Somma-Vesuvius volcano analog. Considering the velocity and diameter ratios suggests that models 09 and 06 , along with the asymmetrical and heavier model 08 , also approximate the behavior of Somma-Vesuvius quite well (Fig. 7e). If the diameter ratio and the ratio of the areas are also considered, it can be clearly seen that model 08 is the best Somma-Vesuvius analog. This last evidence supports the use of the denser medium (50\% sand $-50 \%$ bulking agent) to represent the volcanic edifice (Fig. $7 \mathrm{f}$ ).

The FE simulations of the analog models were run for a simulation time of $3 \mathrm{~h}$ (reflecting the run time of the analog models), and the results were output at intervals of $0.5 \mathrm{~h}$. FE simulations of the analog models reproduced the general subsidence of the whole edifice and the uplift of a circular ring around the edifice base observed in the models. The simulations also reproduced the diffuse uplift affecting a larger area for the 
364 models with smaller scale lengths (models 01 and 06 in Fig. 8). This correspondence was visible when comparing the vertical deformation profiles (Fig. 8). As for the analog models, we now focus our discussion on the simulation that showed results most representative of Somma-Vesuvius.

Figure 9 shows the results obtained for the FE simulation corresponding to the analog model 08 (model from Castaldo \& De Matteo, 2020), as it was considered as the analog model that best reproduces the deformation affecting Somma-Vesuvius. In this case, similar to the results of the analog model, the FE simulation results had a slightly high uplift value at the volcanic edifice base. In the sector close to the Somma rim, we postulated that this occurred due to the heavier load generated by the presence of the high density and homogeneous structure of the Somma rim on that side. The area characterized by the most horizontal movement is located at the base of the volcano slopes and in the close surrounding area (Fig. 9). The similarity between the naturalscale (1:1) FE simulation results, reduced-scale simulations, and surface velocities measured by DInSAR confirm that the parameters adopted for the reduced-scale models efficiently reproduced the deformation style affecting Somma-Vesuvius.

\section{Discussion}

The proposed combined approach represents a reliable way to overcome the intrinsic limitations resulting from using a single modeling approach. Specifically, the combination of analog experiments and numerical modeling made it possible to analyze both the kinematic aspects and those relating to stress distribution, significantly clarifying our understanding of the current deformation style of Somma-Vesuvius. Thus, we compared the modeling results with both ground-based measurements and remote sensing data.

The analog models could reproduce the overall Somma-Vesuvius ground deformation pattern but did not include local effects, such as the development of individual fractures or other details. Therefore, analog modeling provides a "low pass filtered" representation of the active deformation processes of long-term deformation patterns. To compute both the stress distribution and deformation affecting Somma-Vesuvius in FE simulations, we used the parameters derived from the analog modeling, which are a simplification of the actual case, as they do not consider the existence of structural discontinuities and/or lateral mechanical heterogeneity. Thus, in the FE modeling, we chose to consider the mean velocity field rather than displacements.

By analyzing the long-term deformation processes affecting Somma-Vesuvius, we followed the approach proposed by van Wyk de Vries and Matela (1998). We calculated the dimensionless numbers $\left(\Pi_{3}\right.$ and $\left.\Pi_{5}\right)$ for the real volcanic edifice shape and those for each of our models. We plotted our results along with the results of different deformation styles based on the distributions of $\Pi_{3}$ versus those of $\Pi_{5}$ (van Wyk de Vries \& Matela, 1998; Fig. 10). The points related to the real Somma-Vesuvius edifice fell in the black ellipse plotted in Figure 10. Our dimensionless analysis placed SommaVesuvius in a field with high $\Pi_{3}$ and $\Pi_{7}$ values, defined as "volcano and basement spreading" (Fig. 10).

The deformation velocity, area and diameter values of model 08 (Figs. 7a-c), which are based on geometrical characteristics, showed good conformity with the corresponding values from Somma-Vesuvius, suggesting that this model can be regarded as a good approximation of the actual volcano. Therefore, from the deformation pattern of model 08, it can be said that Somma-Vesuvius shows typical features of a spreading process, such as (i) onset of normal faults in the summit region of the edifice (Merle \& Borgia, 
4131996 (Fig. 1a and 11) and (ii) a pronounced symmetrical uplift at the base of the edifice 414 (Fig. 11). Features typical of a sagging deformation should also develop, such as (i) an encircling trough at the base of the edifice (Byrne et al., 2013; Fig. 11), (ii) a peripheral flexural bulge (Kervyn et al., 2010; Fig. 11), and (iii) an uprising of the ductile material along with the fracture opening at the base of the brittle layer as a consequence of the extension generated at the brittle-ductile interface due to the subsidence of the edifice (Fig. 11).

420 In conclusion, we argue that the Somma-Vesuvius edifice is affected by a hybrid sagging/spreading deformation style, with a dominance of spreading over sagging. This spreading dominance is demonstrated by the development of near-radial shear fractures on the edifice slopes rather than the formation of semi-circular, tensile, and shear fractures, which are typical features of a sagging-dominated deformation process (see Fig. 11). Based on the comparison of the vertical deformations retrieved from our analog (Fig. 12a) and FE simulations (Fig. 12c) with the DInSAR LOS mean velocity (Fig. 12b), it can be observed that the proposed modeling procedure very well reproduces the current ground deformation pattern of Somma-Vesuvius. Also, these results show a good fit between our FE model and the DInSAR measurements. In detail, both the analog and FE models, as well as and the DInSAR measurements showed an overall subsidence of the whole edifice along with an uplift in a circular ring at the edifice base. Additionally, structures compatible with the compression of the SW-sector (i.e., the opposite side to

\section{Conclusions}

Our approach supports the integration of different modeling techniques as a successful method to reliably estimate parameters related to the ground deformation patterns in volcanoes. This integrated approach effectively increases the possibility of better understanding the variables affecting volcanic systems and could also be applied to other geodynamic settings. Our models reproduced the real mean velocities of the Somma-Vesuvius volcano as determined from DInSAR LOS, and demonstrated that the volcano is affected by a hybrid sagging-spreading deformation style, characterized by a predominance of spreading. The strong subsidence in the region of the Somma caldera rim and the most significant uplift along the adjacent base of the edifice illustrate that the edifice asymmetry influences the deformation pattern because it affects the geometry of the structures forming and evolving on the volcano.

The recognition of the active spreading processes at Somma-Vesuvius has substantial consequences for inferring the evolution of volcanic activity as the decreasing of the volcanic explosive index (VEI), due to the establishment of a tension regime condition that significantly reduces the loading stress on magmatic reservoir systems. This vertical load reduction could have favored the ascent of less evolved magmatic bodies with a consequent impact on the chemistry of erupted products and consequently on the explosivity index of volcanic eruptions (Borgia et al., 2005). during its quiescent phase is valuable for understanding the future changes in its deformation pattern due to volcanic reactivation processes. Since a renewed activity will interact with the present deformation field, changing and increasing the deformation of the area, the knowledge of the current deformation process affecting Somma-Vesuvius is definitely a key point for a reliable volcanic surveillance system. 
Journal of Geophysical Research-Solid Earth

462 


\section{Appendix A}

464 All the models (Fig. A1) showed the general subsidence of the volcanic edifice

465 and the general uplift of the surrounding area, but were characterized by different 466 deformation rates. The majority of the models, especially the larger ones, showed a 467 flexural bulge around the volcano and radial faults cutting the edifice from the center to 468 the slopes. The symmetric models (i.e., models 02, 03, 05, 07, and 10) showed an 469 almost symmetric deformation pattern, and some of those were characterized by the 470 formation of "flower faults" (e.g., models 05 and 07), which is typical of a spreading 471 deformation process (Merle \& Borgia, 1996).

472 In model 02 , the whole volcanic edifice was characterized by a significant subsidence 473 with values ranging from 0.75 to $1.0 \mathrm{~cm}$. Few radial faults cut the edifice and an uplift 474 ring surrounds it, with values ranging from 0.75 to $1.0 \mathrm{~cm}$.

475 Model 03 was characterized by a subsidence of the volcanic edifice and an uplift of the 476 surrounding area as it occurred in model 02 but, in this case, the subsidence and uplift 477 were less prominent due to the thicker brittle layer.

478 In model 05, the volcanic edifice deformed with a typical spreading deformation style: 479 subsidence of the volcano, forming a moderate flexural bulge of the surrounding area 480 and radial "leaf" faults.

481 Model 07, built with a thinner brittle layer than model 05, was characterized by a 482 significant subsidence, by a wide area affected by uplift (with the formation of several 483 bulging surrounding the edifice base) and by the formation of a lot of radial faults 484 cutting the lower sides of the slopes.

485 Model 10 showed a subsidence focused on the center of the volcano, while some faults 486 cut the edifice from the center to the slopes, and a lot of flexural bulge in the area 487 surrounding the volcanic edifice. 

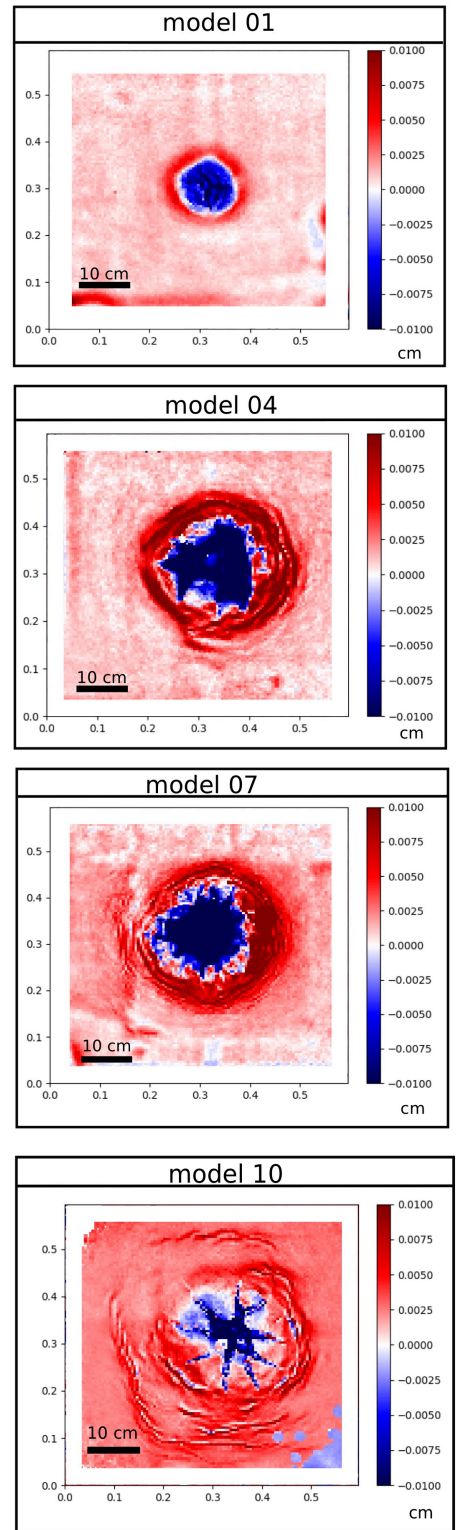
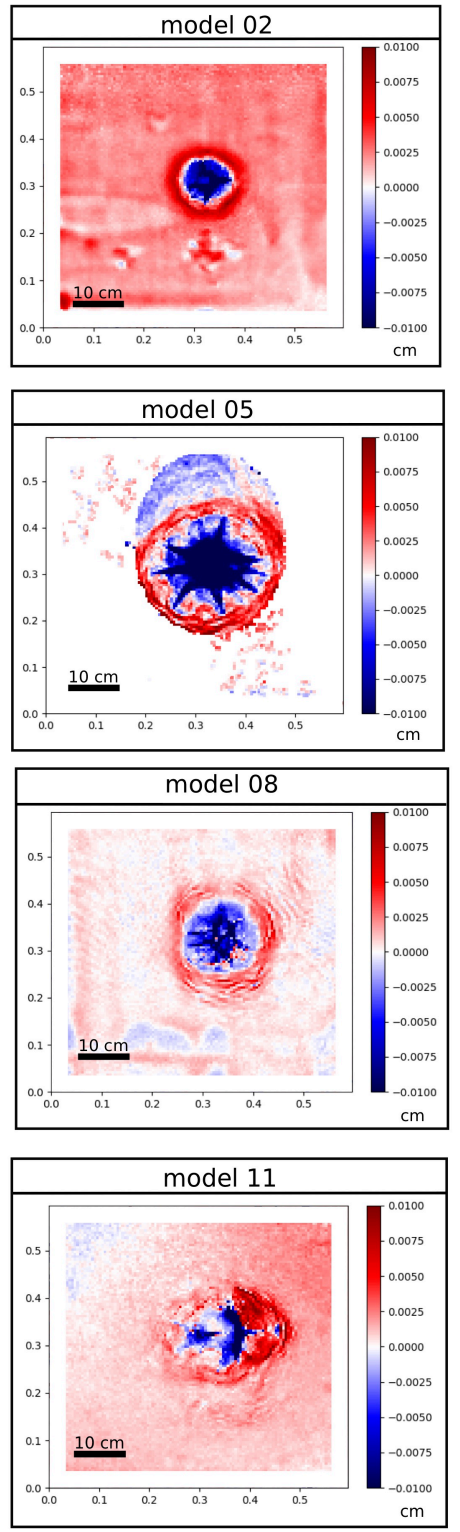
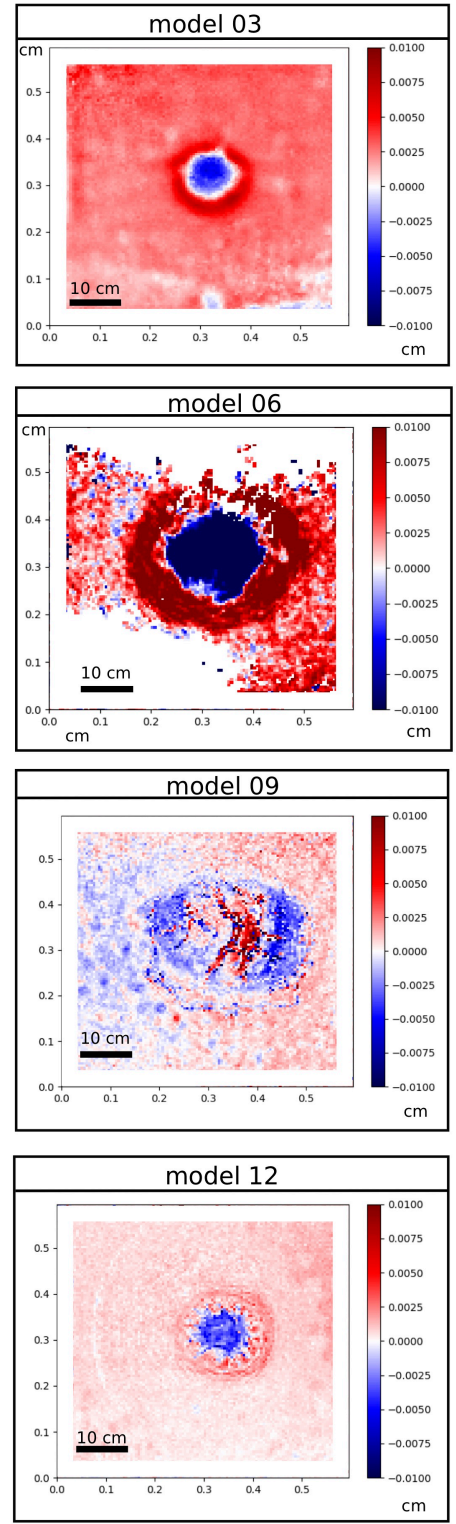

Figure A1. Vertical deformation of the performed twelve analog models. For the model parameters, see Table 3.

Code and data availability: the code and data necessary to run our FE model named model08 are stored in a Zenodo data repository (Castaldo \& De Matteo, 2020). The DInSAR mean velocity measurements of the Somma-Vesuvius volcano from 1992 to 2010 are available in the Zenodo data repository (Tizzani et al., 2020). The dense points clouds dataset of the "best" analog model (model 08) are collected in the Zenodo data repository (De Matteo \& Massa, 2021).

\section{Acknowledgment}

This research was financially supported by FRA Università degli Studi del Sannio (P. I. B. Massa) and partially by the Civil Protection Department of Italy.

We thank the European Space Agency (ESA) for providing ERS-1/2 and ENVISAT SAR data. Analog modeling was performed at the "Laboratorio di Geologia Strutturale 
e Modellistica" hosted at the Department of Science and Technogy-Università degli Studi del Sannio (Italy).

Thanks are due to the Editor Isabelle Manighetti, the anonymous expert Associate Editor, Olivier Galland and Benjamin Van Wyk de Vries for their precious suggestions 489 that greatly improved the manuscript. 


\section{References}

Andronico, D., Calderoni, G., Cioni, R., Sbrana, A., Sulpizio, R., \& Santacroce, R. (1995), Geological map of Somma-Vesuvius volcano, Period. Mineral, 64(1-2), 77-78.

Berardino, P., Fornaro, G., Lanari, R., \& Sansosti, E. (2002), A new algorithm for surface deformation monitoring based on small baseline differential SAR interferograms. IEEE Transactions on Geoscience and Remote Sensing, 40(11), 23752383.

Barenblatt, G. I. 2003. Scaling, Cambridge, Cambridge University Press.

Bianco, F., Castellano, M., Milano, G., Ventura, G., \& Vilardo, G. (1998), The SommaVesuvius stress field induced by regional tectonics: Evidences from seismological and mesostructural data. Journal of Volcanology and Geothermal Research, 82(1-4), 119218.

Bonasia, V., Del Pezzo, E., Pingue F., Scandone, R., \& Scarpa R. (1985), Eruptive history, seismic activity and ground deformation at Mt. Vesuvius, Italy. Annales Geophysicae, 395-406.

Borgia, A., Delaney, P. T., \& Denlinger R. P., (2000), Spreading volcanoes. Annual Review of Earth and Planetary Sciences, 28(1), 539-570.

Borgia, A. \& van Wyk de Vries, B. (2003), The volcano-tectonic evolution of Concepción, Nicaragua. Bulletin of Volcanology, 65(4), 248-266. Doi: 10.1007/s00445002-0256-8.

Borgia, A., Tizzani, P., Solaro, G., Manzo, M., Casu, F., Luongo, et al. (2005), Volcanic spreading of Vesuvius, a new paradigm for interpreting its volcanic activity. Geophysical Research Letters, 32(3). DOI: 10.1029/2004GL 022155.

Brocchini, D., Principe, C., Castradori, D., Laurenzi, M. A., \& Gorla L. (2001), Quaternary evolution of the southern sector of the Campania Plain and early SommaVesuvius activity: Insights from the Trecase 1 well. Mineralogy and Petrology, 73(1), 67-91.

Buckingham, E. (1914), On physically similar systems; illustrations of the use of dimensional equations. Physical Review, 4(4), 345-376. Doi: https://doi.org/10.1103/PhysRev.4.345

Buckingham, E. (1915), The principle of similitude. Nature, 96(2406), 396-397. doi:10.1038/096396d0.

Byrne, P. K., Holohan E. P., Kervyn M., van Wyk de Vries B., Troll V. R., \& Murray J. B. (2013), A sagging-spreading continuum of large volcano structure. Geology, 41(3), 339-342.

Castaldo, R. \& De Matteo, A. (2020), Vesuvius deformation modeling, Comsol numerical model code. [Dataset ]Zenodo. http://doi.org/10.5281/zenodo.4009368.

D’Auria, L., Esposito, A.M., Bascio, D.L., Ricciolino, P., Giudicepietro, F., Martini, M., et al. (2013), The recent seismicity of Mt. Vesuvius: Inference on seismogenic processes. Annals of Geophysics, 56(4), S0442. doi:10.4401/ag-6448.

D'Auria, L., Massa, B., \& De Matteo, A. (2014a), The stress field beneath a quiescent stratovolcano: The case of mount Vesuvius. Annals of Geophysics, 56(4), 1181-1199. DOI: $10.1002 / 2013 J B 010792$ 
De Matteo, A. \& Massa, B. (2021), Points clouds of the best Somma-Vesuvius gravitative deformation process analog model. [Dataset] Zenodo. 10.5281 /zenodo. 5383327 .

Delcamp, A., de Vries, B.V., \& James, M.R. (2008), The influence of slope and substrata on volcano spreading. Journal of Volcanology and Geothermal Research, 177(4), 925-943.

Farr, T.G., Rosen, P.A., Caro, E., Crippen, R., Duren, R., Hensley, S., et al. (2007), The shuttle radar topography mission, Reviews of Geophysics, 45(2), RG2004. doi:10.1029/2005RG000183.

Gibbings, J. C. (2011), Dimensional Analysis. London, Springer.

Handin, J. (1996), Strength and ductility. GSA Memoirs, 223-290.

Hubbert, M.K. (1937), Theory of scaled models as applied to the study of geological structures. Bulletin of the Geological Society of America, 48(10), 1459-1520.

Jaeger, J.C., \& Cook, N.G.W. (1971), Fundamentals of Rock Mechanics. Chapman and Hall: London, UK; ISBN 0412220105.

James, M.R., How, P., \& Wynn, P.R. (2015), Pointcatcher software: Analysis of glacial time-lapse photography and integration with multi-temporal digital elevation models. $\mathrm{J}$ Journal of Glaciology, 62(231), 159-169. doi:10.1017/jog.2016.27

Jashemsky, W.F. (2002), The Vesuvian Sites Before AD 79, The Archeological, Literary, And Epigraphical Evidence, In The Natural History Of Pompeii. Edited by W.F. Jashemsky and F.G. Meyer, 6-28, Cambridge University Press, New York.

Kavanagh, J.L., Engwell, S.L., \& Martin, S.A (2018), A review of laboratory and numerical modelling in volcanology. Solid Earth, 9(2), 531-571. https://doi.org/10.5194/se-9-531-2018

Kervyn, M., Boone, M. N., van Wyk de Vries, B., Lebas, E., Cnudde, V., Fontijn, K., \& Jacobs, P. (2010), 3D imaging of volcano gravitational deformation by computerized Xray microtomography. Geosphere, 6(5), 482-498. DOI: 10.1130/GES00564.1.

Koyi H. (1997), Analog modelling: From a qualitative to a quantitative technique-a historical outline. Journal of Petroleum Geology, 20(2), 223-238.

Lanari, R., De Natale, G., Berardino, P., Sansosti, E., Ricciardi, G.P., Borgst. S., Pingue, F., \& Troise C. (2002), Evidence for a peculiar style of ground deformation inferred at Vesuvius volcano. Geophysical Research Letters, 29(9), 6-1. doi: 10.1029/2001GL01414571.

Marturano, A., Aiello, G., \& Barra, D. (2013), Somma-Vesuvius ground deformation over the last glacial cycle. Journal of Volcanology and Geothermal Research, 255, 9097. http://dx.doi.org/10.1016/j.jvolgeores.2013.02.007

Massa, B, D’Auria, L., Cristiano, E., \& De Matteo, A. (2016), Determining the stress field in active volcanoes using focal mechanisms. Frontiers in Earth Science, 4, 103. DOI: $10.3389 /$ feart.2016.00103

Merle, O., \& Borgia, A. (1996), Scaled experiments of volcanic spreading. Journal of Geophysical Research: Solid Earth, 101(B6), 13805-13817.

Montanari, D., Agostini, A., Bonini, M., Corti, G., \& Del Ventisette, C. (2017), The use of empirical methods for testing granular materials in analog modeling. Materials, 
10(6), 635. https://doi.org/10.3390/ma10060635.

Newhall, C.G., \& Self, S. (1982), The volcanic explosivity index (VEI): An estimate of explosive magnitude for historical volcanism. Journal of Geophysical Research, 87(C2), 1231-1238. https://doi.org/10.1029/JC087iC02p01231.

Pedersen, R., \& Sigmundsson, F. (2004), InSAR based sill model links spatially offset areas of deformation and seismicity for the 1994 unrest episode at Eyjafjallajökull volcano. Iceland. Geophysical Research Letters, 31(14). DOI: 10.1029/2004GL020368

Ramberg, H. (1981), Gravity, Deformation and the Earth's Crust. 2nd ed. Academic Press, London.

Rosi, M., Santacroce, R., \& Sbrana, A. (1987), Geological Map of the Somma-Vesuvius Volcanic Complex (Scale 1:25000), CNR, PF Geodinamica, L Salomone, Roma.

Santacroce, R. (Ed.) (1987), Somma-Vesuvius. 114, 249 pp., CNR, Rome, Italy.

Sbrana, A., Cioni, R., Marianelli, P., Sulpizio, R., Andronico, D., \& Pasquini, G. (2020), Volcanic evolution of the Somma-Vesuvius Complex (ITALY). Journal of Maps, 16(2), 137-147. DOI: 10.1080/17445647.2019.1706653.

Segall, P. (2013). Volcano Deformation and Eruption Forecasting. London: Geological Society; Special Publications. 380, 85-106. https://doi.org/10.1144/SP380.4.

Tizzani, P., Manconi, A., Zeni, G., Pepe, A., Manzo, M., Camacho, A., \& Fernández, J. (2010), Long-term versus short-term deformation processes at Tenerife (Canary Islands). Journal of Geophysical Research: Solid Earth, 115(B12). B12412.doi:10.1029/2010JB007735.

Tizzani, P., Pepe, S., \& Castaldo, R. (2020), DInSAR-SBAS mean velocity data of Somma-Vesuvius Volcano from 1992 to 2010. [Dataset] Zenodo. http://doi.org/10.5281/zenodo.3901247.

Umakoshi, K., Shimizu, H., \& Matsuwo, N. (2001), Volcano-tectonic seismicity at Unzen Volcano, Japan, 1985-1999. Journal of Volcanology and Geothermal Research, 112(1-4), 117-131. DOI: 10.1016/S0377-0273(01)00238-4.

van Wyk de Vries, B., \& Borgia A. (1996), The role of the basement in volcano deformation. In: McGuire, W.J. et al. (Eds.), Volcano Instability on the Earth and other Planets. Geo. Soc. London Spec. Publ. 110, 95-110.

van Wyk de Vries, B. \& Matela R. (1998), Styles of volcano-induced deformation: Numerical models of substratum flexure, spreading and extrusion. Journal of Volcanology and Geothermal Research, 81(1-2), 1-18.

van Wyk de Vries, B. \& Francis P.W. (1997), Catastrophic collapse at stratovolcanoes induced by slow volcano spreading. Nature, 387(6631), 387-390.

Ventura, G. \& Vilardo, G. (1999), Slip tendency analysis of the Vesuvius faults: Implication for the seismotectonic and volcanic hazard assessment. Geophysical Research Letters, 26(21), 3229-3232.

Weijermars, R. (1986), Flow behaviour and physical chemistry of bouncing putties and related polymers in view of tectonic laboratory applications. Tectonophysics, 124(3-4), $325-358$. 


\begin{tabular}{|c|c|c|}
\hline$\prod 1$ & $\frac{\text { volcano height }}{\text { volcano diameter }}$ & $\frac{\mathrm{H}_{\mathrm{v}}}{\mathrm{D}_{\mathrm{v}}}$ \\
\hline \multirow{2}{*}{$\prod^{2}$} & volcano height & $\mathrm{H}_{\mathrm{v}}$ \\
\hline & $\overline{\text { ductile layer thickness }}$ & $\overline{\mathrm{H}_{\mathrm{d}}}$ \\
\hline \multirow{2}{*}{$\prod 3$} & volcano diameter & $\overline{D_{v}}$ \\
\hline & $\overline{\text { ductile layer thickness }}$ & $\overline{\mathrm{H}_{\mathrm{d}}}$ \\
\hline \multirow{2}{*}{$\prod 4$} & brittle layer thickness & $\mathrm{H}_{\mathrm{b}}$ \\
\hline & $\overline{\text { ductile layer thickness }}$ & $\overline{\mathrm{H}_{\mathrm{d}}}$ \\
\hline$\prod 5$ & Coefficient of internal friction & $\tan \Phi$ \\
\hline \multirow{2}{*}{ П6 } & volcano bulk density & $\mathrm{Bd}_{\mathrm{v}}$ \\
\hline & $\overline{\text { ductile layer density }}$ & $\overline{\rho_{d}}$ \\
\hline \multirow{2}{*}{$\prod 7$} & viscous force & $\eta \cdot \mathrm{v}$ \\
\hline & $\overline{\text { Mohr Coulomb failure resistanc }}$ & {$\left[\tau_{0}\left(1+2 \tan \Phi \sqrt{\mathrm{H}_{\mathrm{b}}}\right)+\mathrm{g} \mathrm{Bd}_{\mathrm{V}} \mathrm{H}_{\mathrm{v}} \tan \Phi\left(1+\mathrm{H}_{\mathrm{b}}\right)\right] \cdot \mathrm{H}_{\mathrm{v}}$} \\
\hline \multirow{2}{*}{$\prod 8$} & inertial force & $\mathrm{v} \cdot \rho_{\mathrm{d}} \cdot \mathrm{H}_{\mathrm{d}}$ \\
\hline & $\overline{\text { viscous force }}$ & $\eta$ \\
\hline
\end{tabular}

Table 1. Description of the $\prod$ numbers and their formulas. For a description of the symbols, see Table 2.

$\because$ and $\underset{\square}{ }$ represent the gravity acceleration and velocity, respectively.

\begin{tabular}{cllll}
\hline \multirow{2}{*}{ Parameters } & Descriptions & Values & & Units \\
\cline { 3 - 5 } & Models & Natural equivalent & $\mathrm{m}$ \\
\hline $\mathrm{Hd}$ & Ductile layer thickness & $0.004-0.007$ & $400-700$ & $\mathrm{~m}$ \\
\hline $\mathrm{Hv}$ & Brittle layer thickness & $0.002-0.005$ & $200-500$ & $\mathrm{~m}$ \\
\hline $\mathrm{Dv}$ & Volcano height & 0.012 & 1200 & $\mathrm{~m}$ \\
\hline$\tau_{0}$ & Volcano diameter & 0.122 & 12200 & $\mathrm{~Pa}$ \\
\hline$\Phi$ & Cohesion & 65 & 107 & $\circ$ \\
\hline$\eta$ & Angle of internal friction & 39 & 30 & $\mathrm{~Pa} \mathrm{~s}$ \\
\hline $\mathrm{Bd}_{\mathrm{b}}$ & Ductile layer viscosity & $2 \times 104$ & $1 \times 1019$ & $\mathrm{~kg} \mathrm{~m}^{-3}$ \\
\hline $\mathrm{Bd}_{\mathrm{v}}$ & Brittle layer bulk density & 1550 & 2580 & $\mathrm{~kg} \mathrm{~m}^{-3}$ \\
\hline$\rho_{\mathrm{d}}$ & Dolcano bulk density & $1550-1950$ & $2580-3245$ & $\mathrm{~kg} \mathrm{~m}^{-3}$ \\
\hline
\end{tabular}

Table 2. Parameter values adopted for the modeling and corresponding natural equivalent. 


\begin{tabular}{|c|c|c|c|c|c|c|c|c|}
\hline Model & $\mathrm{Hd}(\mathrm{cm})$ & $\mathrm{Hb}(\mathrm{cm})$ & $\mathrm{Hv}(\mathrm{cm})$ & Dv $(\mathrm{cm})$ & Symmetry & Edifice & oulk density $\left(\mathrm{kg} \mathrm{m}^{-3}\right.$ & \\
\hline 01 & 0.7 & 0.2 & 1.1 & 12.2 & no & $\begin{array}{l}1550 \\
70: 30)\end{array}$ & (sand:K-feldspar & $=$ \\
\hline 02 & 0.7 & 0.2 & 1.1 & 12.2 & yes & $\begin{array}{l}1550 \\
70: 30)\end{array}$ & (sand:K-feldspar & $=$ \\
\hline 03 & 0.7 & 0.5 & 1.1 & 12.2 & yes & $\begin{array}{l}1550 \\
70: 30)\end{array}$ & (sand:K-feldspar & $=$ \\
\hline 04 & 0.7 & 0.5 & 2.2 & 24.4 & no & $\begin{array}{l}1550 \\
70: 30)\end{array}$ & (sand:K-feldspar & $=$ \\
\hline 05 & 0.7 & 0.5 & 2.2 & 24.4 & yes & $\begin{array}{l}1550 \\
70: 30) \\
\end{array}$ & (sand:K-feldspar & $=$ \\
\hline 06 & 0.7 & 0.2 & 2.2 & 24.4 & no & $\begin{array}{l}1550 \\
70: 30)\end{array}$ & (sand:K-feldspar & $=$ \\
\hline 07 & 0.7 & 0.2 & 2.2 & 24.4 & yes & $\begin{array}{l}1550 \\
70: 30)\end{array}$ & (sand:K-feldspar & $=$ \\
\hline 08 & 0.7 & 0.2 & 1.1 & 12.2 & no & $\begin{array}{l}1950 \\
50: 50) \\
\end{array}$ & (sand:K-feldspar & $=$ \\
\hline 09 & 0.7 & 0.2 & 2.2 & 24.4 & no & $\begin{array}{l}1950 \\
50: 50)\end{array}$ & (sand:K-feldspar & $=$ \\
\hline 10 & 0.7 & 0.2 & 2.2 & 24.4 & yes & $\begin{array}{l}1950 \\
50: 50) \\
\end{array}$ & (sand:K-feldspar & $=$ \\
\hline 11 & 0.4 & 0.2 & 2.2 & 24.2 & no & $\begin{array}{l}1950 \\
50: 50)\end{array}$ & (sand:K-feldspar & $=$ \\
\hline 12 & 0.4 & 0.2 & 1.1 & 12.2 & no & $\begin{array}{l}1950 \\
50: 50)\end{array}$ & (sand:K-feldspar & $=$ \\
\hline
\end{tabular}

Table 3. Parameter values (Table 2) for the analog models. 
(a)

(a)
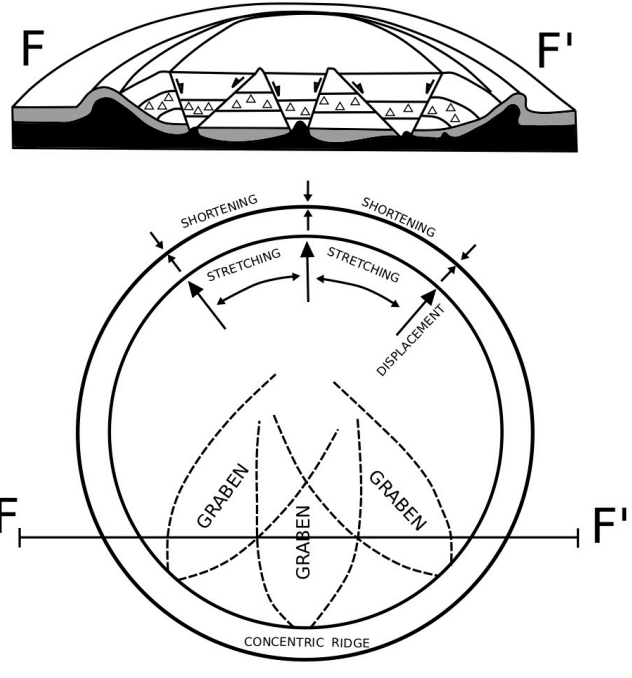

(b)

SPREADING

1

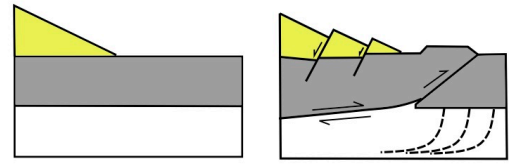

BASEMENT EXTRUSION

2

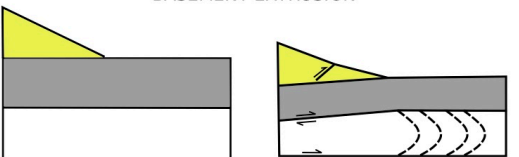

3

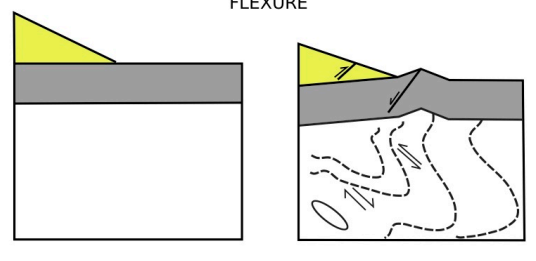

$\square$ ductile layer $\square$ brittle layer $\square$ edifice

Figure 1. (a) Scheme of the volcanic spreading process (after Merle and Borgia, 1996). On the top, a cross-section of the initial stage shows the flow of the weak layer (in black) and the horst-and-graben structures developing within the volcanic edifice. On the bottom, a surface projection shows the relationship between the volcano-tectonic structures and the strain pattern associated with the spreading process: radial displacement, concentric stretching in the volcano, and radial shortening in the substratum surrounding the volcano (from Merle and Borgia,1996, modified). (b) Schematic diagrams of the principal deformation styles. The dotted lines show the movement of the ductile material. The small arrows indicate the movement directions. 1: Spreading deformation. 2: Basement extrusion (or sagging) deformation. 3: Flexure deformation (from van Wyk de Vries and Mattela, 1998, modified). 


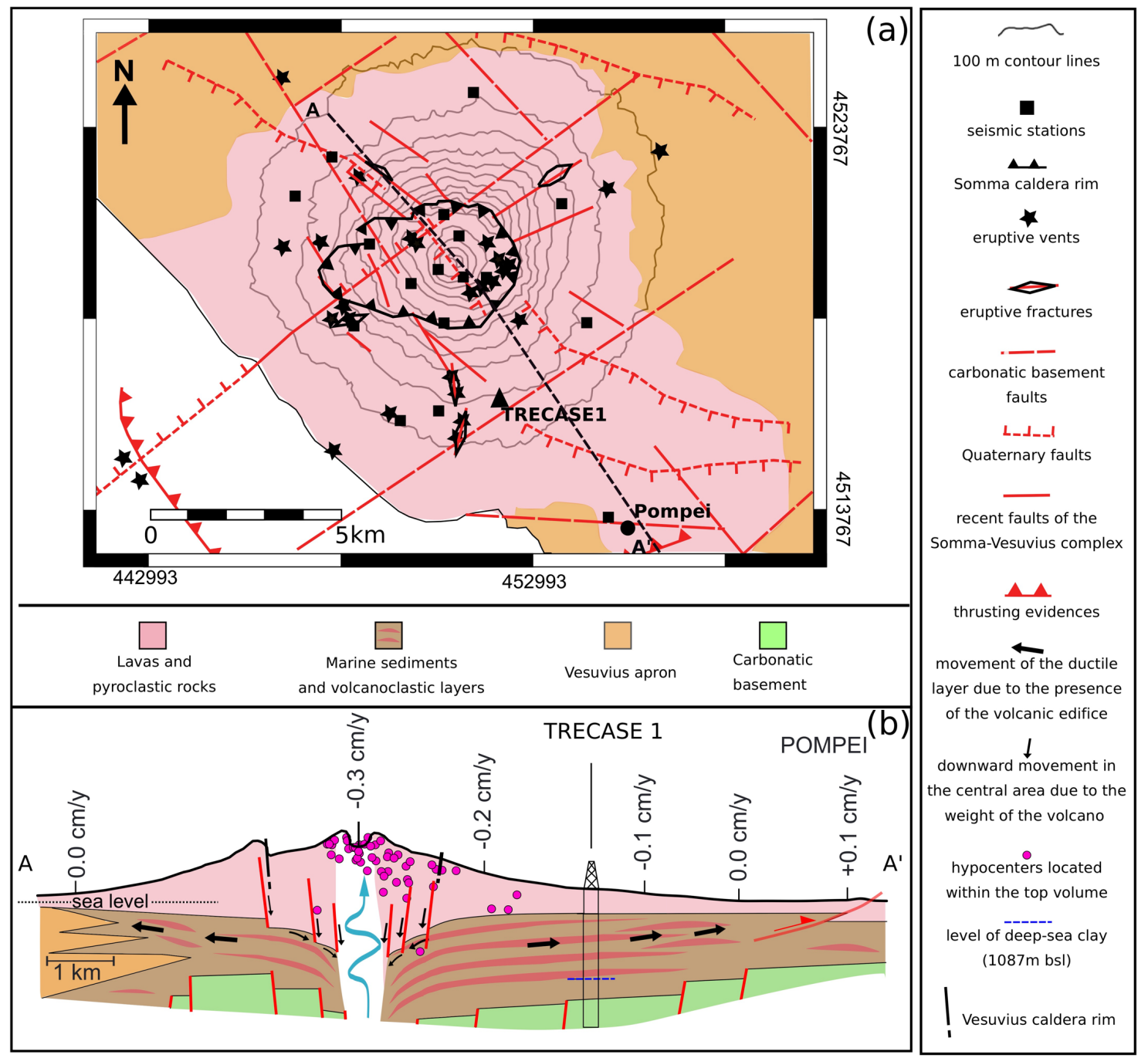

Figure 2. (a) Map of the Vesuvius area with an outline of the major tectonic features. The coordinates are in UTM WGS84. Data from Ippolito et al. (1973), Bianco et al. (1998), Bruno and Rapolla (1999), Ventura and Vilardo (1999), Orsi et al. (2003), Borgia et al. (2005), and Milia et al. (2012). (b) Schematic cross-section along with A$\mathrm{A}^{\prime}$. The numbers along the profile indicate the vertical ground deformation rate. Along the Trecase well, we schematically reported the stratigraphic succession. The top layer consists of lavas interbedded with pyroclastic rocks, the intermediate layer mostly consists of sandy and clayey marine deposits interbedded with volcaniclastic layers, and the bottom layer consists of carbonatic rocks of the basement. 
524

525

526

527

528

529

530

531

532

533

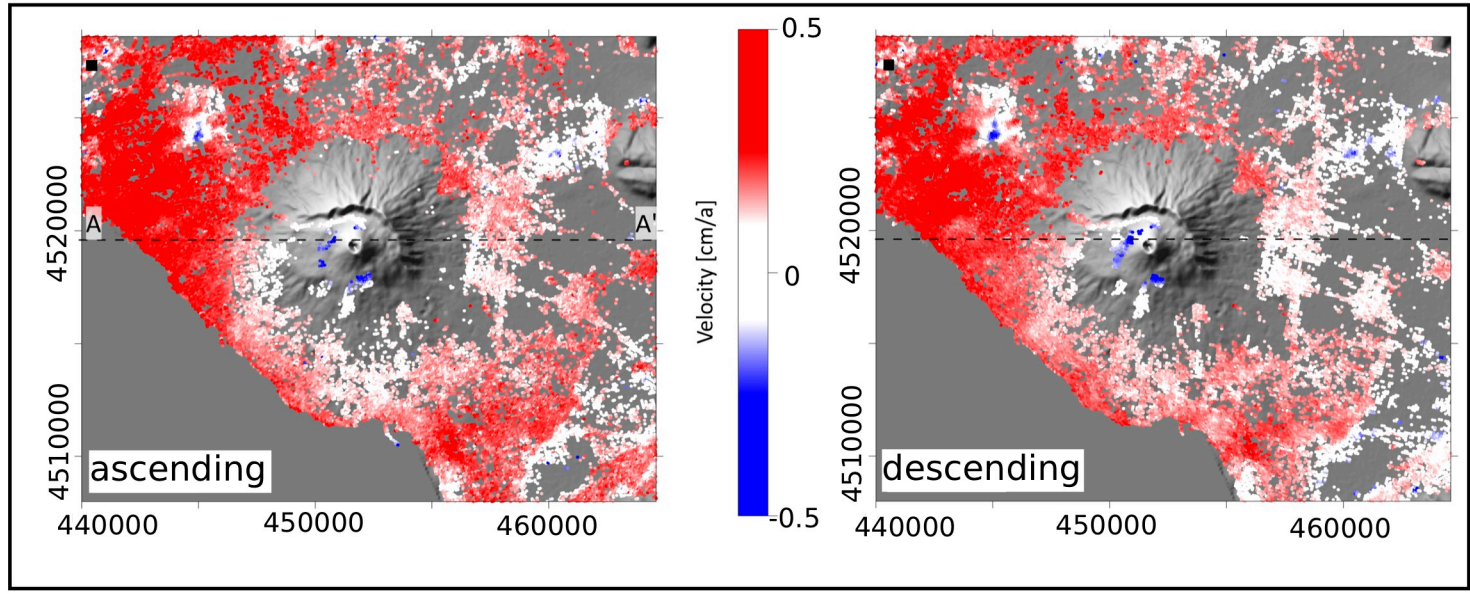

Figure 3. LOS projection components (ascending and descending) of the mean deformation velocity observed at Somma-Vesuvius from 1993 to 2010 (achieved by DInSAR-SBAS processing).

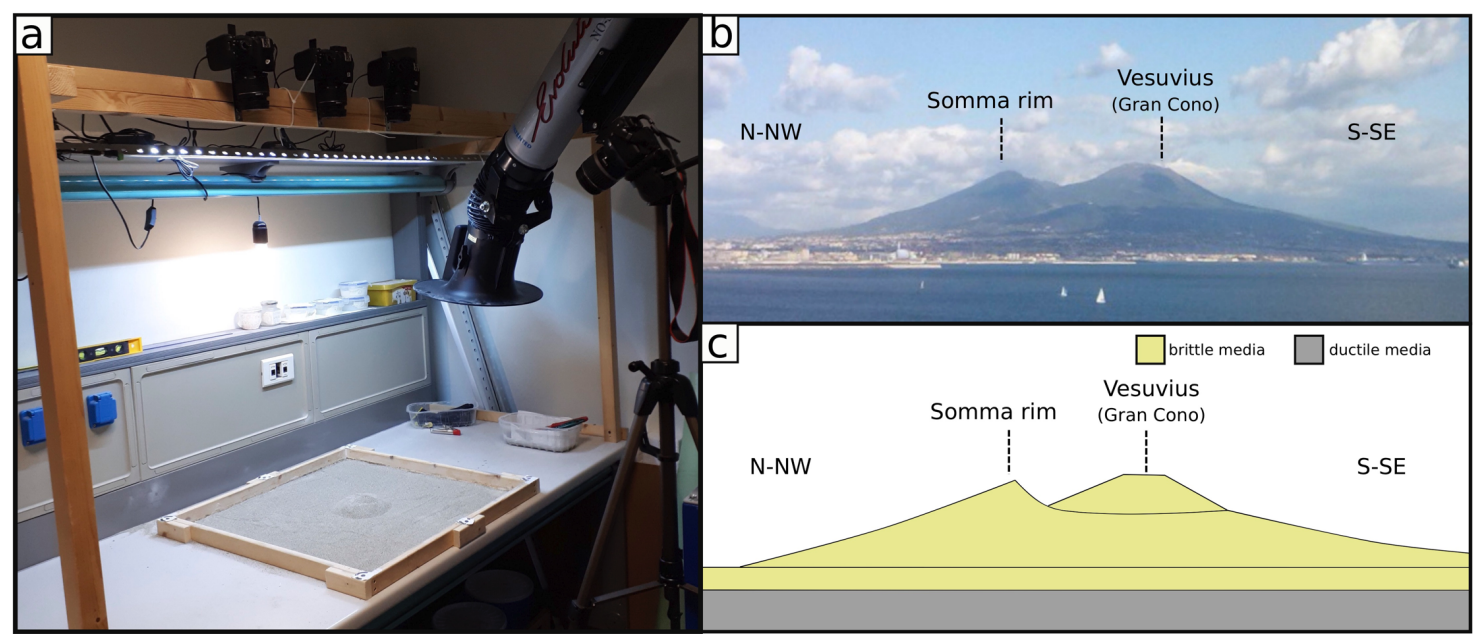

Figure 4. (a) Experimental setup of the analog model, (b) profile of the SommaVesuvius edifice (for scale, the summit is $1281 \mathrm{~m}$ above sea level), and (c) a sketch of the double truncated cone geometry used to represent the edifice in the experiments. 


\section{4}

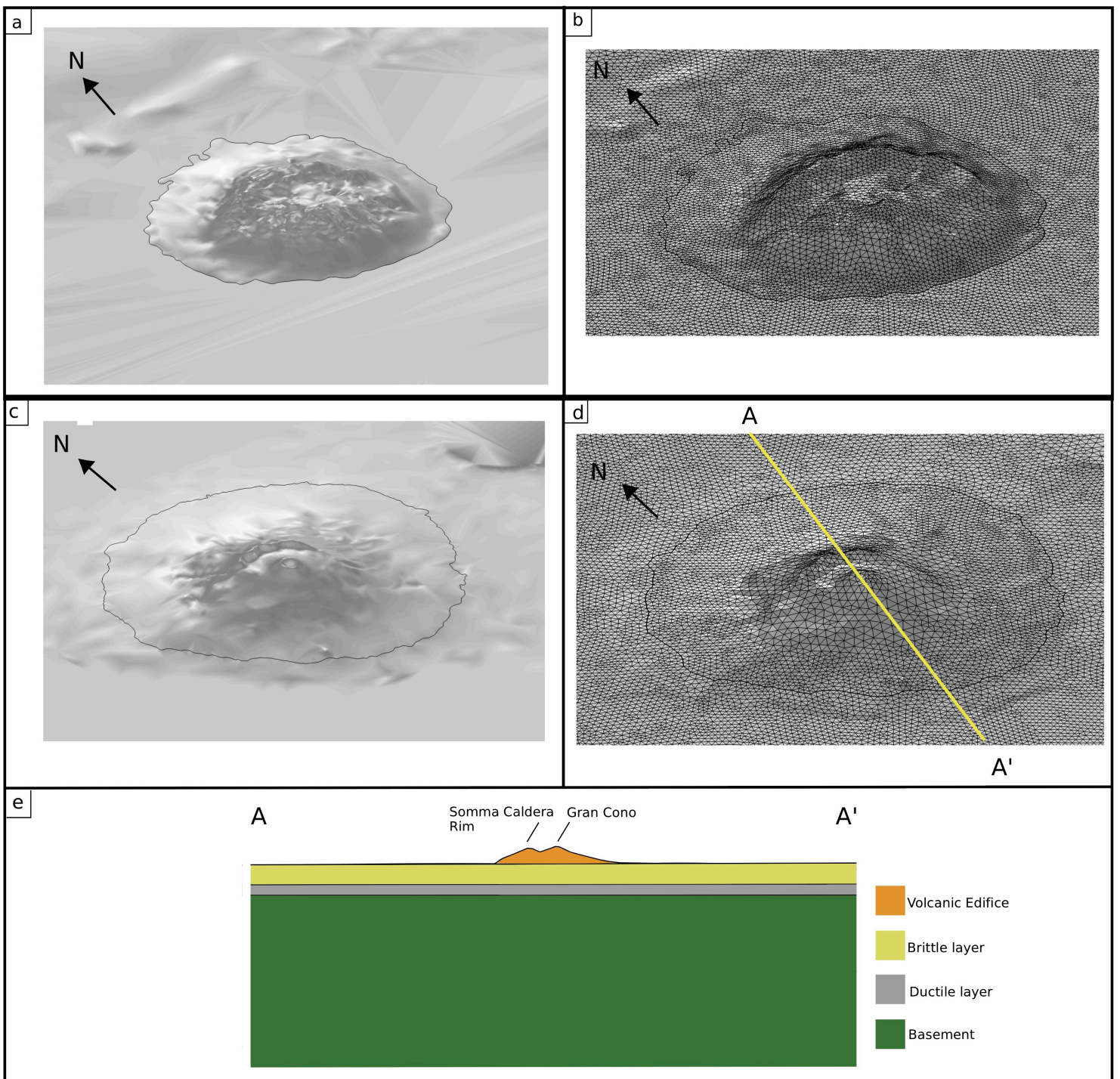

Figure 5. (a) 3D geometry and (b) mesh of the tetrahedral elements used for the FE 537 modeling related to, as an example, the analog model 08. (c) 3D geometry and (d) mesh 538 of the tetrahedral elements used for the finite element model related to the real Somma539 Vesuvius. (e) Sketch of the geometry used to represent the real Somma-Vesuvius in the 540 FE simulations, taken along with AA' (shown in panel d). 

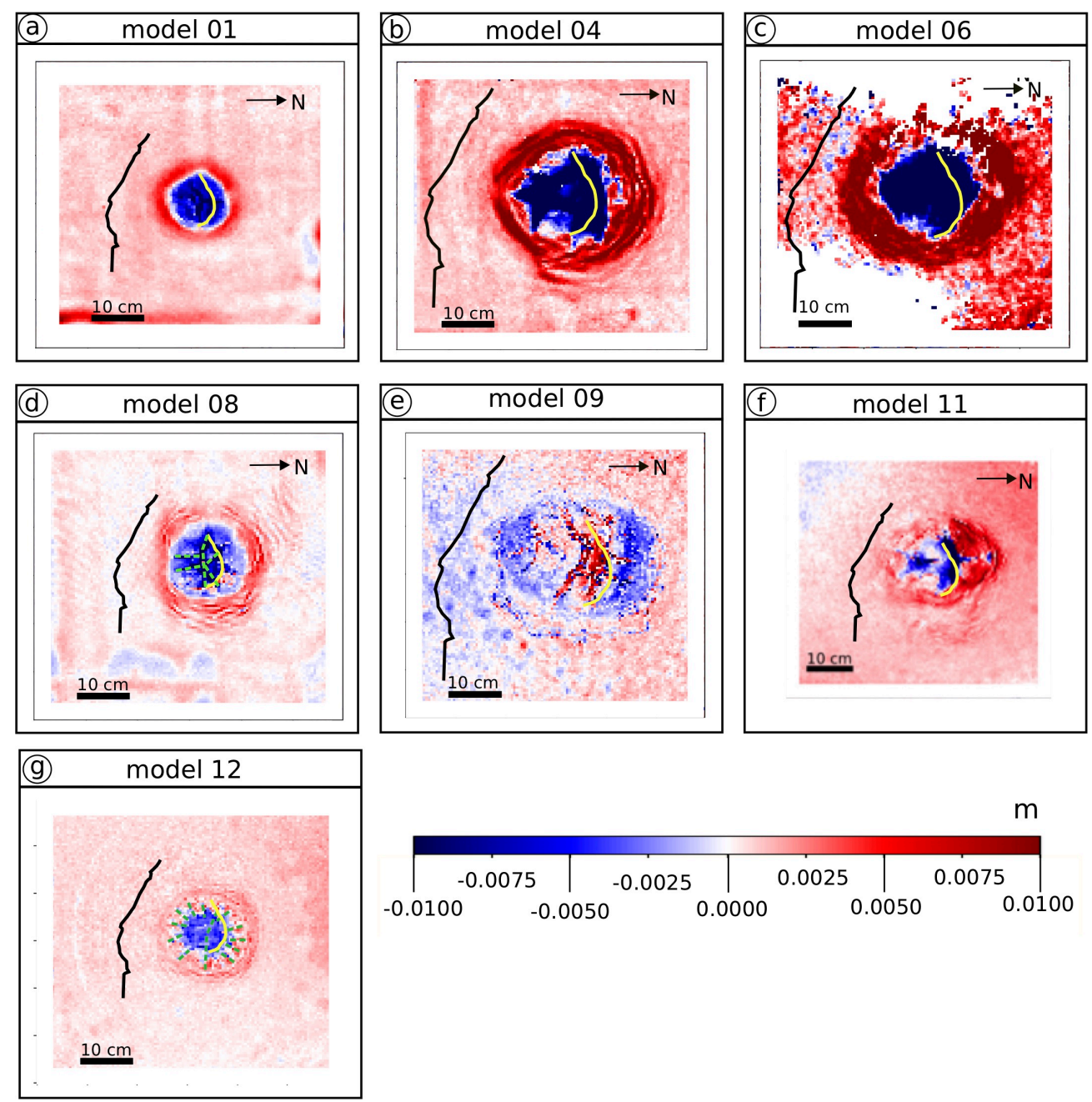

541

542 Figure 6. Vertical deformations of the selected analog models. The black and yellow 543 lines represent the coastline and the Somma caldera rim, respectively. 

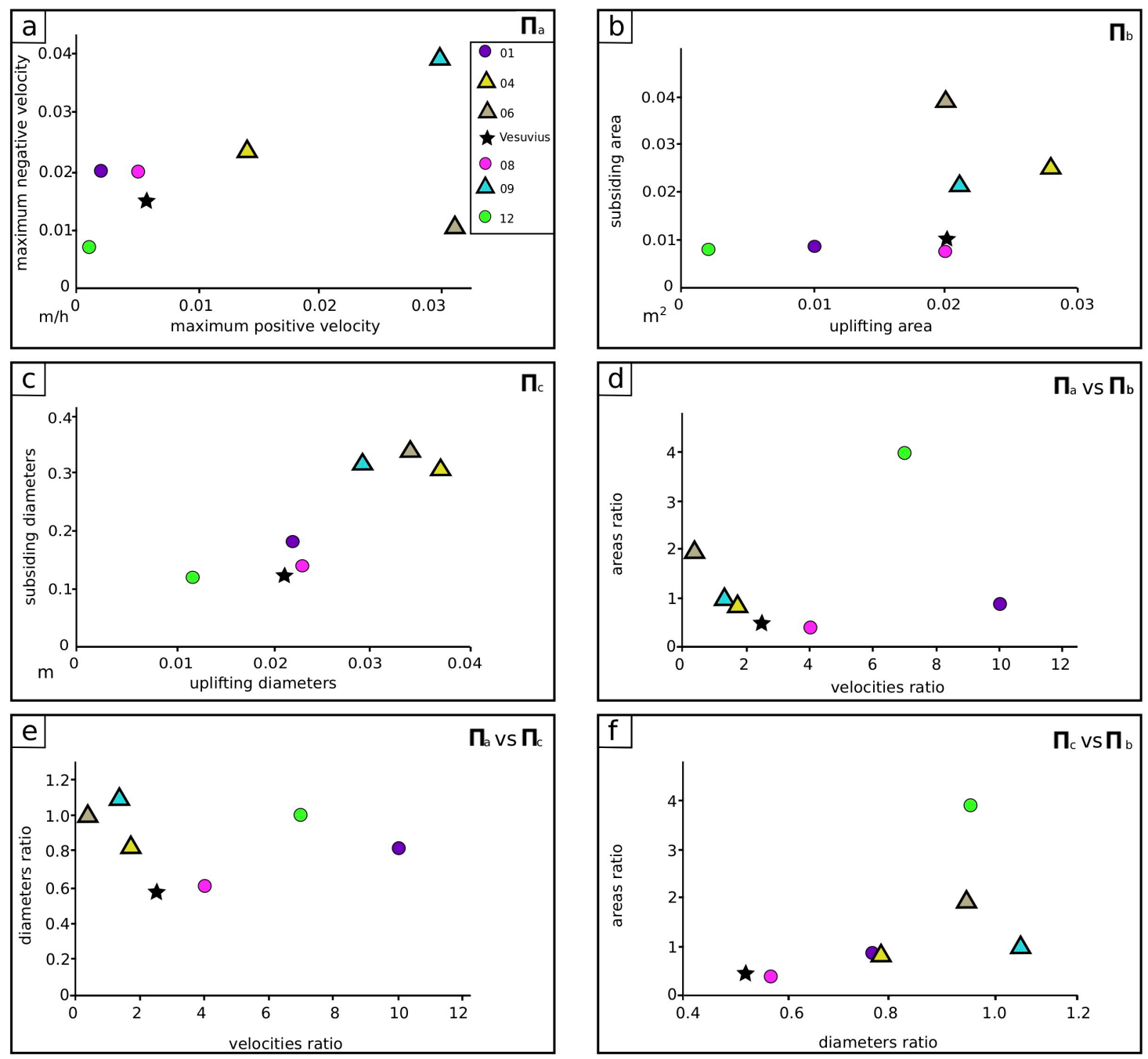

546 Figure 7. Relationships between the main parameters of the analog models, FE models, 547 and scaled monitoring data of real Somma-Vesuvius volcano (see the main text 548 paragraph 2.1 and Table 2 for details). (a), (b), and (c) show the relationship between 549 the parameters defining IIa, IIb, and IIc, respectively. 


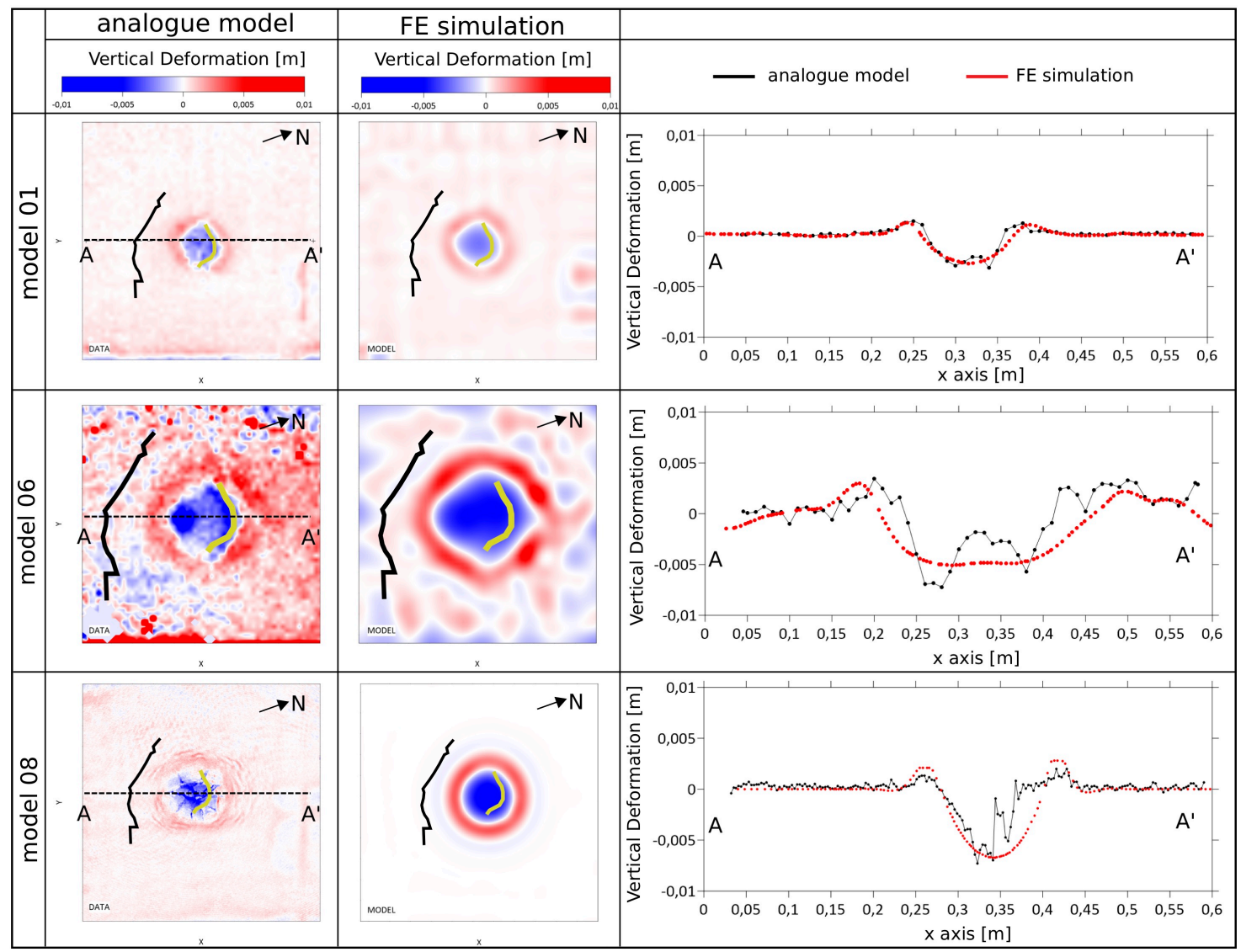

552 Figure 8. Left column: retrieved vertical deformation of the selected analog models. Central column: Equivalent FE simulations. The black and yellow lines represent the coastline and Somma caldera rim, respectively. Right column: Profiles showing the comparison between the results of the analog and FE models, taken along the dashed line AA' (shown in left panels).
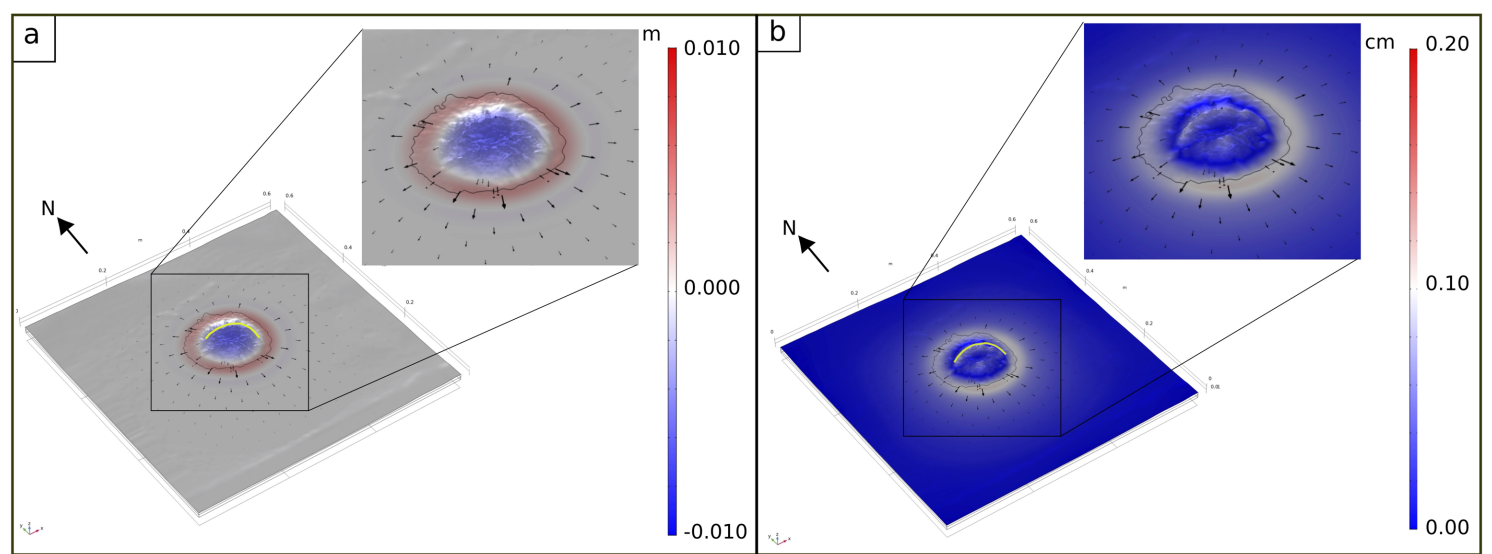

Figure 9. (a) Vertical (scale in 10-3) and (b) horizontal (scale in 10-4) deformation of the FE model 08. The black arrows represent the horizontal movement direction; their size is proportional to the movement amount. 


\section{2}

563

564

565

566

567

568

569

570

571

572

573

574

575

576

577

578

579

580

581

582

583

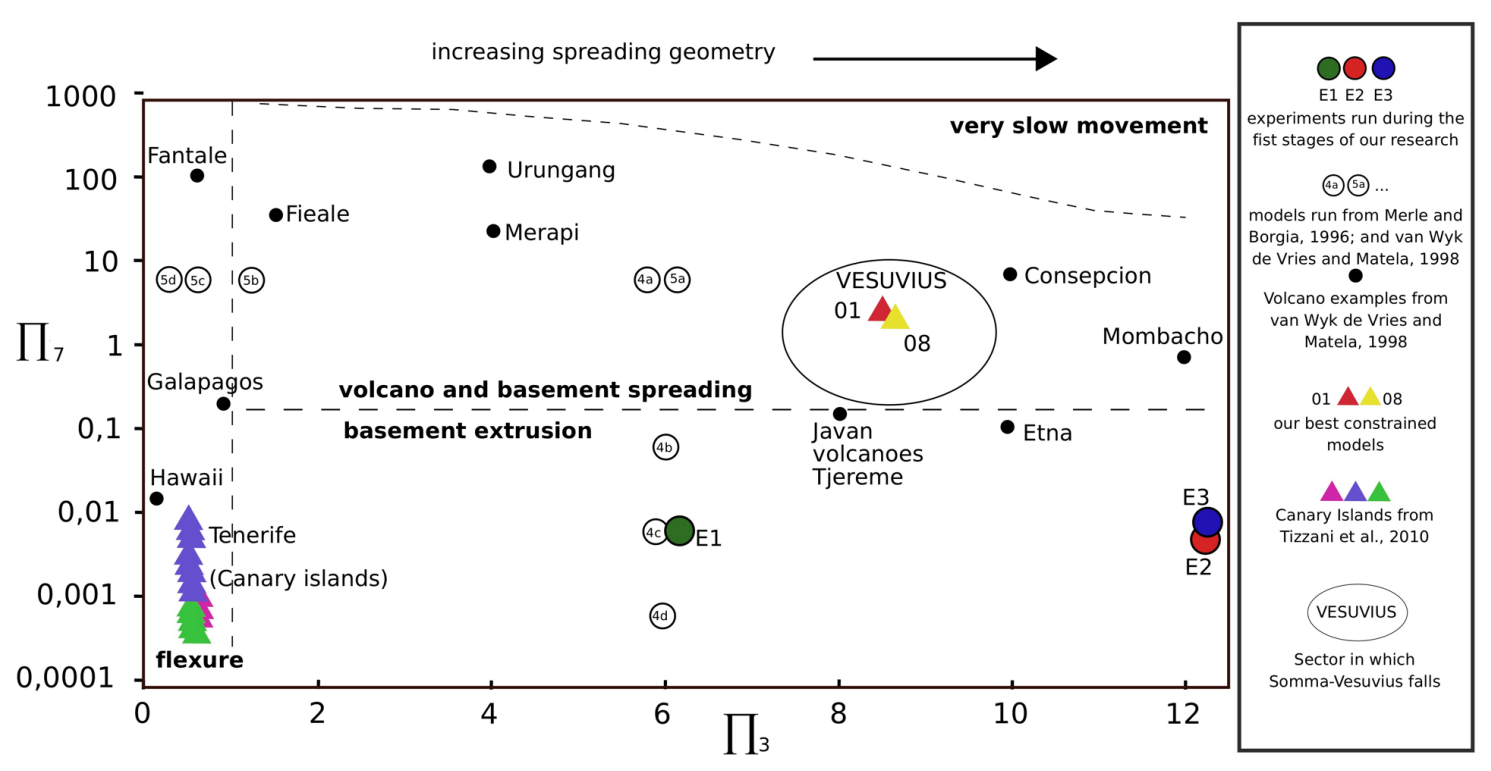

Figure 10. Plot of $\Pi 3$ against $\Pi 7$ illustrating the fields occupied by flexure, spreading, and extrusion deformations. Somma-Vesuvius (Vesuvius) is represented by an ellipse reflecting the uncertainty of a few geometrical parameter values, such as the thickness of the ductile layer. The models above discussed and not plotted here fall in sectors of the diagram too far from the areas of interest (modified from Wyk de Vries and Matela, 1998). 


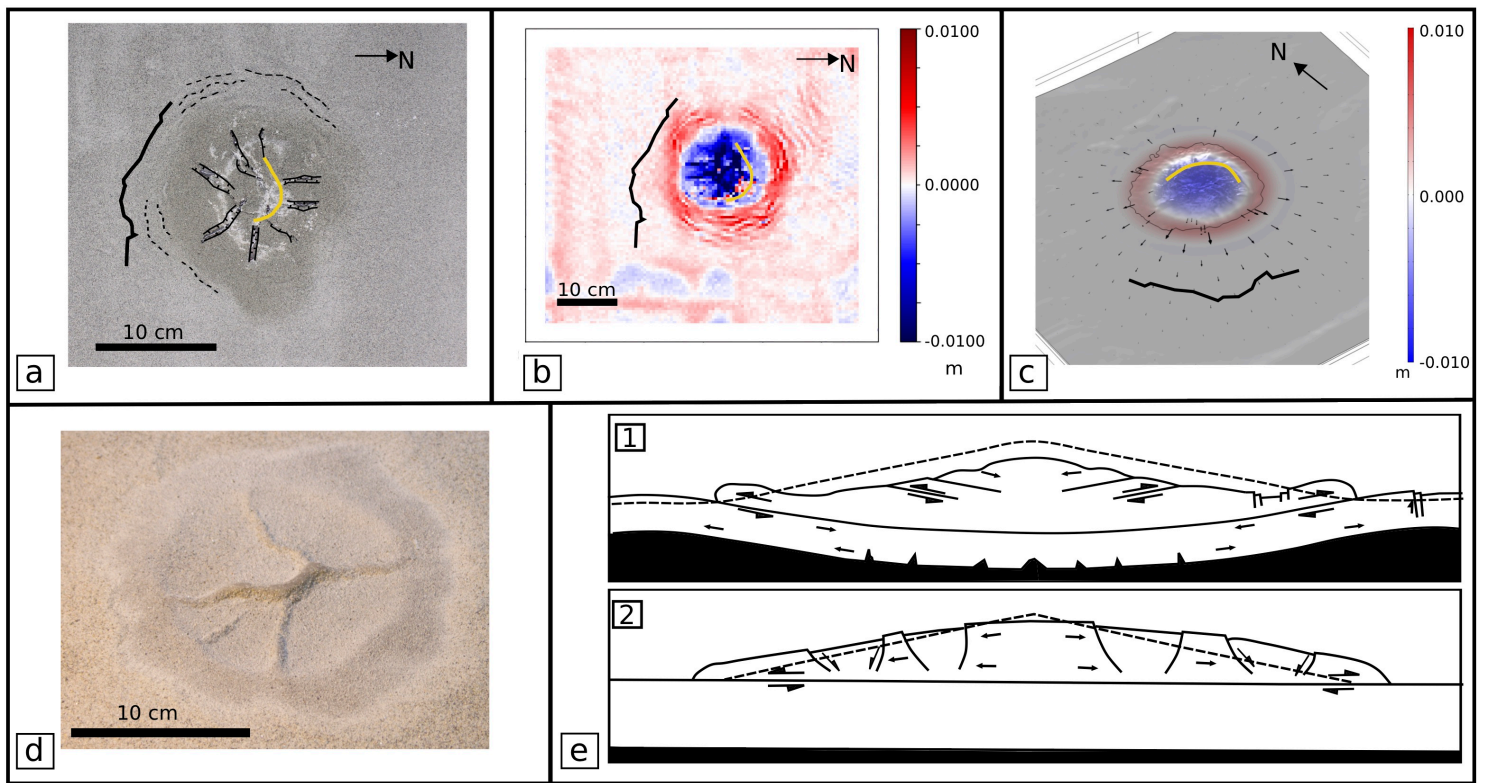

584

585

586

587

588

589

590

591

592

593

594

595

596

597

598

Figure 11. (a) Top view of model 08 at the end of the experiment, peripheral flexural bulge (dashed lines), radial faults, and graben are highlighted. The black and yellow lines represent the coastline and Somma caldera rim, respectively. (b) Vertical deformation maps of model 08 (dense points cloud in De Matteo \& Massa, 2021). (c) Vertical deformation of the FE model 08; the black and yellow lines represent the coastline and Somma caldera rim, respectively, while the black arrows represent the horizontal movement direction. (d) Top view of the ductile layer of model 08 at the end of the experiment: the uprising of the ductile material along with the fracture opening at the base of the brittle layer are evident. (e) Schematic block diagrams of the hybrid sagging-spreading architecture (1) and endmember spreading architecture (2) (modified from Byrne et al., 2013).

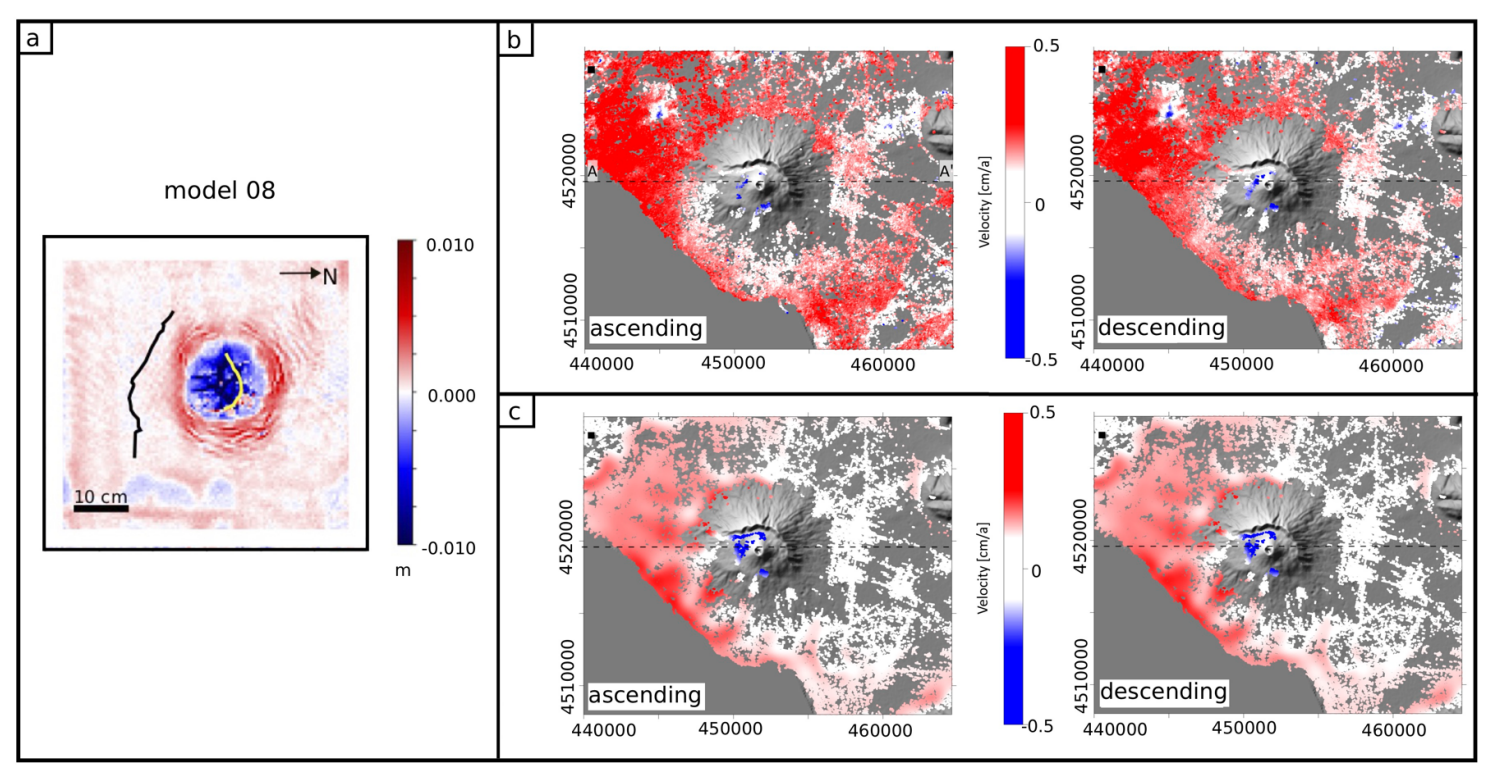

Figure 12. (a) Vertical deformation of the analog model 08. (b) LOS projection components (ascending and descending ones) of the mean deformation velocity observed at Somma-Vesuvius from 1993 to 2010 by DInSAR-SBAS processing. (c) 
602 LOS projection components of the mean deformation velocity modeled with the FE 603 method at a natural scale $(1: 1)$.

604

605 